\title{
DISTRIBUIÇÃO DE MASSA MOLECULAR DE ÁCIDOS HÚMICOS E PROMOÇÃO DO CRESCIMENTO RADICULAR ${ }^{(1)}$
}

\author{
Natália de Oliveira Aguiar ${ }^{(2)}$, Luciano Pasqualoto Canellas ${ }^{(3)}$, \\ Leonardo Barros Dobbss ${ }^{(4)}$, Daniel Basílio Zandonadi ${ }^{(5)}$, Fábio \\ Lopes Olivares ${ }^{(6)} \&$ Arnoldo Rocha Façanha ${ }^{(6)}$
}

\begin{abstract}
RESUMO
Os ácidos húmicos (AH) estimulam diretamente vários processos fisiológicos que promovem o crescimento vegetal, especialmente do sistema radicular. $O$ conhecimento da natureza química e do papel de $\mathrm{AH}$ na expressão de efeitos biofertilizantes e bioestimulantes é fundamental para o desenvolvimento de insumos biológicos à base de ácidos húmicos. O objetivo deste trabalho foi avaliar uma possível relação entre a distribuição de massa molecular aparente de $\mathrm{AH}$ isolados de vermicomposto e a magnitude de resposta na promoção do crescimento radicular. Para isso, foram obtidas subfrações (SF) dos AH por meio de cromatografia preparativa por exclusão de tamanho em gel de Sephadex G-50 (CGE). O processo preparativo foi validado pelo uso da cromatografia líquida de alta performance por exclusão de tamanho (HPSEC). As cinco frações obtidas foram testadas em diferentes concentrações $(0 ; 0,0001 ; 0,001 ; 0,003 ; 0,005$; e $0,01 \mathrm{~mol} \mathrm{~L}^{-1} \mathrm{de} \mathrm{C}$ ) quanto à sua capacidade de estimular o crescimento radicular de plantas de Arabidopsis thaliana (ecótipo col. 4). Para plantas de milho (Zea mays hyb. UENF 506-6) foi utilizada a dose de 0,002 $\mathrm{mol} \mathrm{L}^{-1}$ de C. O modelo quadrático descreveu a indução do crescimento radicular de Arabidopsis e a dose de $\mathrm{AH}$, sendo $0,00511 \mathrm{~mol} \mathrm{~L}^{-1}$ de $\mathrm{C}$ o ponto de inflexão médio. Na concentração ótima, foi observada correlação inversa e significativa entre distribuição de massa molecular e indução do número de raízes laterais em Arabidopsis. No entanto, outros atributos, como área e comprimento radicular, não sofreram influência da
\end{abstract}

\footnotetext{
(1) Recebido para publicação em dezembro de 2008 e aprovado em julho de 2009.

${ }^{(2)}$ Graduanda de Agronomia, Universidade Estadual do Norte Fluminense Darcy Ribeiro (UENF) - Centro de Ciências e Tecnologias Agropecuárias (CCTA) - Laboratório de Solos (LSOL). Núcleo de Desenvolvimento de Insumos Biológicos para a Agricultura - NUDIBA/UENF. Av. Alberto Lamego 2000, CEP: 28602-013 Campos dos Goytacazes (RJ). Bolsista IC - PIBIC CNPq. E-mail: nd.aguiar@gagro.uenf.br

(3) Professor Associado, UENF/LSOL-NUDIBA. Bolsista do CNPq. E-mail: canellas@uenf.br

(4) Doutorando do Programa de Pós-graduação em Produção Vegetal. UENF/LSOL-NUDIBA 1dobbss@uenf.br

(5) Doutorando do Programa de Pós-graduação em Biociências e Biotecnologia: UENF. E-mail: daniel@uenf.br

(6) Professor Associado, Laboratório de Biologia Celular e Tecidual (LBCT), UENF. Bolsista do CNPq. E-mails: fabioliv@uenf.br; arnoldo@uenf.br
} 
massa molecular aparente. Em plântulas de milho, foi observado aumento no número de sítios de mitose e raízes laterais tanto no tratamento com $\mathrm{AH}$ como com suas subfrações. A atividade da $\mathrm{H}^{+}$-ATPase de membrana plasmática foi significativamente alterada pelo $\mathrm{AH}$, porém não ocorreu o mesmo com todas as subfrações. A atividade de estimulação do crescimento radicular parece estar mais relacionada com a estrutura química das substâncias húmicas do que com a distribuição de massa molecular dos agregados húmicos.

Termos de indexação: efeitos físiológicos, estrutura e conformação, cromatografia em gel, HPLC.

\title{
SUMMARY: MOLECULAR WEIGHT DISTRIBUTION OF HUMIC ACIDS AND ROOT GROWTH PROMOTION
}

\begin{abstract}
Humic acids (HA) directly stimulate several physiological processes that promote plant growth, particularly of the root system. Knowledge about the chemical nature and the role of $H A$ in the effects observed under biofertilization and biostimulation is essential to develop HA-based biological resources. The aim of this study was to evaluate a possible relationship between the distribution of the apparent molecular weight of HA isolated from vermicompost and the response in root growth promotion. HA sub-fractions were obtained through preparative chromatography by size exclusion using Sephadex gel G-50 gel (CGE). The preparative process was validated by high-performance size-exclusion chromatography (HPSEC). The five sub-fractions were tested at different concentrations $(0 ; 0.0001 ; 0.001 ; 0.003 ; 0.005$; and $0.001 \mathrm{~mol} \mathrm{~L}^{-1} \mathrm{C}$ ) for their capacity to stimulate root growth of Arabidopisis thaliana (ecotype col 4) seedlings. For maize seedlings (Zea mays hybrid UENF 506-6) a rate of $0.002 \mathrm{~mol} \mathrm{~L}^{-1} \mathrm{C}$ was used. The quadratic model described the relationship between root growth induction and $H A$ dose in Arabidopsis; $0.00511 \mathrm{~mol} \mathrm{~L}^{-1} \mathrm{C}$ was the average inflection point. At the optimum concentration, a significant negative correlation between molecular weight distribution and the number of lateral roots induced in A. thaliana was observed. However, other root traits, e.g., area and length, were not influenced by the apparent molecular weight of fractions. An increase in the number of mitotic and lateral root emission was observed for maize seedlings, both for the treatment with $H A$ as well as with the sub-fractions. The $H^{+}$-ATPase activity of plasma membrane was significantly affected by $H A$, although differently in the sub-fractions. The stimulating activity of root growth seems to be more related to the chemical structure of humic substances than to the distribution of molecular weight of the humic aggregates.
\end{abstract}

Index terms: physiological effects, structure and conformation, gel chromatography, HPLC.

\section{INTRODUÇÃO}

Plantas com crescimento radicular estimulado têm condições de explorar maior volume de solo, facilitando a adaptação em ambientes de baixa fertilidade, com restrição de água ou, ainda, em sistemas de cultivos orgânicos, nos quais a liberação de nutrientes nem sempre é imediata e dependente da mineralização da matéria orgânica. As substâncias húmicas (SH), além de influenciarem as reações no solo (Canellas et al., 2008b), também exercem efeitos diretos sobre a fisiologia das plantas (Vaughan \& Malcolm, 1985), especialmente sobre o crescimento radicular (Nardi et al. 2002; Canellas et al., 2002).

Muscolo et al. (2007) sugeriram que somente SH com dimensões compatíveis para atingir o apoplasto são fisiologicamente ativas. No entanto, processos bioquímicos intracelulares, como a regulação das bombas de prótons (Canellas et al., 2002; Zandonadi et al., 2006) e a estimulação de enzimas ligadas ao ciclo de Krebs (Nardi et al., 2007), foram alterados pela presença de SH com distribuição de massa/ tamanho molecular maior, como os ácidos húmicos (AH) - a fração alcalino-solúvel que precipita em meio fortemente ácido. Embora a promoção da emergência de raízes laterais por diversos tipos de $\mathrm{AH}$ seja bem documentada (Canellas et al., 2002; Zandonadi et al., 2006; Dobbss et al., 2007), a relação entre a bioatividade e a distribuição de massa/tamanho molecular é relativamente pouco estudada.

Existem vários métodos disponíveis para determinação da distribuição de massa/tamanho molecular das SH, como ultracentrifugação, viscosimetria, crioscopia, espalhamento de luz, 
difração de raios X, osmometria por pressão de vapor, entre outros (Cabaniss et al., 2000). As técnicas cromatográficas baseadas no princípio da exclusão por tamanho em gel (CGE) ou em cromatografia líquida de alta performance por exclusão de tamanho (HPSEC) são os métodos mais frequentemente usados, devido à simplicidade na obtenção de resultados (Janos, 2003). A fase estacionária mais utilizada na CGE em baixa pressão são os géis de Sephadex ${ }^{\circledR}$. Outros efeitos não relacionados à exclusão por tamanho podem ocorrer durante o processo cromatográfico, devido à interação da fase móvel com a estacionária. Essas interações eletrostáticas podem ser reduzidas com a utilização de tampões alcalinos e força iônica adequada. Uma discussão detalhada sobre mecanismos secundários envolvidos na cromatografia por exclusão de tamanho de SH pode ser encontrada em vários trabalhos (Swift \& Posner, 1971; Saito \& Hayano, 1979; Ralph \& Catcheside, 1996; Tonelli et al., 1997; Swift, 1999; De Nobili \& Chen, 1999; Janoš \& Zatørepálková, 2007).

Atualmente tem sido enfatizado o uso de colunas rígidas, cujo empacotamento é compatível com a instrumentação da HPLC. Assim, a HPSEC tornouse uma ferramenta importante no fracionamento e na caracterização das SH, uma vez que a obtenção de frações húmicas mais homogêneas favorece a elucidação de seu comportamento associativo em solução (Conte \& Piccolo, 1999; Silva et al., 2000; Sierra et al., 2006; Peuravuori \& Pihlaja, 2007).

O objetivo deste trabalho foi avaliar os efeitos das subfrações de massa/tamanho, obtidas de AH oriundos de vermicomposto por CGE preparativa, na promoção do crescimento de raízes de Arabidopsis e milho, identificando possíveis relações entre bioatividade e distribuição de massa molecular.

\section{MATERIAL E MÉTODOS}

\section{Obtenção dos ácidos húmicos (AH)}

Os AH foram isolados de vermicomposto produzido com esterco de curral, utilizando-se $\mathrm{NaOH} 0,1 \mathrm{~mol} \mathrm{~L}^{-1}$ (1:10, v:v) sob atmosfera de $\mathrm{N}_{2}$. Após quatro horas de agitação, o material foi centrifugado $(3.000 \mathrm{~g}, 20 \mathrm{~min})$ e acidificado a $\mathrm{pH} 1,5 \mathrm{com} \mathrm{HCl} 6 \mathrm{~mol} \mathrm{~L}^{-1}$. O material foi novamente centrifugado e o sobrenadante descartado. Os AH foram solubilizados, precipitados por mais duas vezes e tratados por $16 \mathrm{~h}$ com $\mathrm{HCl}: \mathrm{HF}$ diluídos (1:20, v:v). Após centrifugação, os AH foram titulados a pH 7,0 com KOH 0,1 $\mathrm{mol} \mathrm{L}^{-1}$ e submetidos à diálise em tubos de membrana com limite de exclusão de 1.000 Da até o valor da condutividade elétrica da água ser igual ao da água destilada.

\section{Cromatografia preparativa em gel por exclusão de tamanho (CGE)}

O equipamento de baixa pressão para cromatografia preparativa em gel por exclusão de tamanho consistiu de um reservatório para fase móvel, uma coluna de vidro de $40 \mathrm{~cm}$ de comprimento e $0,9 \mathrm{~mm}$ de diâmetro interno, uma bomba peristáltica (BioRAD) e um coletor de frações (BioRad). Foi utilizado um sistema de detecção on-line por ultravioleta (espectrômetro Biorad), operando em $280 \mathrm{~nm}$. A coluna cromatográfica foi empacotada com gel de dextrano Sephadex ${ }^{\circledR}$ (Sephadex G-50). A fase móvel foi preparada com os tampões borato-fosfato $\mathrm{Na}_{2} \mathrm{~B}_{4} \mathrm{O}_{7}$ $\left(0,1 \mathrm{~mol} \mathrm{~L}^{-1}\right), \mathrm{Na}_{4} \mathrm{P}_{2} \mathrm{O}_{7}\left(0,01 \mathrm{~mol} \mathrm{~L}^{-1}\right)$ e $\mathrm{NaCl}$ $\left(0,1 \mathrm{~mol} \mathrm{~L}^{-1}\right)$ e utilizado fluxo de $0,5 \mathrm{~mL} \mathrm{~min}^{-1}$. O volume injetado na coluna foi de $5 \mathrm{~mL}$, numa concentração de $0,5 \mathrm{~g} \mathrm{~L}^{-1}$ de $\mathrm{AH}$. $\mathrm{O}$ pH da fase móvel foi mantido a 7,0 com uso de $\mathrm{NaOH}$ ou $\mathrm{HCl}$ diluídos, quando necessário. As frações obtidas por CEG foram coletadas e submetidas à diálise para retirada dos sais (foi usada uma membrana com limite de exclusão menor do que $1.000 \mathrm{Da}$ ). Após a diálise, foram retiradas alíquotas para determinação do teor de carbono por combustão via úmida (Total Carbon Analyser). Em seguida, as amostras foram congeladas e secas por liofilização.

\section{Determinação da composição elementar}

A caracterização do $\mathrm{AH}$ e suas subfrações foi realizada em analisador elementar automático Perkin Elmer 2400, em amostras de $4 \mathrm{mg}$ de $\mathrm{AH}$ e suas subfrações em duplicata. $\mathrm{O}$ conteúdo de $\mathrm{O}_{2}$ foi determinado por diferença, descontando o teor de cinzas obtido com a incineração de três amostras dos $\mathrm{AH}$ por tratamento em mufla a $700{ }^{\circ} \mathrm{C}$.

\section{Determinação da acidez total, fenólica e carboxílica}

A acidez total foi determinada pelo método do $\mathrm{Ba}(\mathrm{OH})_{2}$ com titulação do excesso com $\mathrm{HCl}$; a acidez carboxílica, pelo tratamento com $\mathrm{Ca}(\mathrm{OAc})_{2}$ e determinação do Ac liberado com $\mathrm{NaOH}$; e a acidez fenólica, por diferença (acidez total - carboxílica), de acordo com método de Schnitzer \& Gupta (1965).

\section{Cromatografia de alta performance por exclusão de tamanho (HPSEC)}

A HPSEC foi utilizada para avaliar a homogeneidade das SF obtidas pela CGE. O sistema de HPLC Shimadzu LC-10ADVP (Tokyo, Japan) consiste de dois detectores em série UV-Vis (Shimadzu) operando a 280 e $360 \mathrm{~nm}$, uma bomba isocrática (Shimadzu) e um loop de $100 \mu \mathrm{L}$ para injeção da amostra. O sistema estava acoplado a um computador, que processava os dados pelo software Class-VP. A separação por exclusão de tamanho se deu através da coluna BioSep- SEC S200 Phenomenex, com $300 \mathrm{~mm}$ de comprimento, 7,8 mm de diâmetro interno e $5 \mu \mathrm{m}$ de diâmetro de poros. A pré-coluna Polysep-GFC-Guard Column, com $35 \mathrm{~mm}$ de comprimento, 7,8 mm de diâmetro interno e 0,2 $\mu \mathrm{m}$ de diâmetro de poros, foi usada para proteger a coluna. 
O tampão fosfato $\left(\mathrm{NaH}_{2} \mathrm{PO}_{4} 0,0625 \mathrm{~mol} \mathrm{~L}^{-1}, \mathrm{pH} 7,0 \mathrm{e}\right.$ força iônica $0,104 \mathrm{~mol} \mathrm{~L}^{-1}$ ) foi usado como eluente, com fluxo de $1,5 \mathrm{~mL} \mathrm{~min}^{-1} \mathrm{em}$ alta pressão. $\mathrm{O}$ volume injetado na coluna foi de $100 \mu \mathrm{L}$ na concentração de $0,5 \mathrm{~g} \mathrm{~L}^{-1}$ de AH. Um grupo de substâncias-padrão MW-GF-200 (Sigma, St. Louis, USA) foi utilizado para calibração da coluna, entre elas citocromo $\mathrm{C}(\mathrm{Mw}$ 12.400 Da), carbono anidrase (29.000 Da), albumina $(66.000 \mathrm{Da})$, desidrogenase (150.000 Da) e $\alpha$-amilase (200.000 Da). O Blue Dextran com Mw de cerca de 2.000.000 Da foi usado para determinação do limite de exclusão, e o $\mathrm{KNO}_{3}$, para determinação do volume total de permeação da coluna. Os valores aparentes de massa molecular foram obtidos a partir do método de Yau et al. (1979), utilizando a seguinte equação:

$$
M w=\frac{\sum h_{i} M_{i}}{\sum h_{i}}
$$

em que $h i$ é a altura do cromatograma da amostra em cada volume $i$. Os valores referentes à $\mathrm{Mw}$ do $\mathrm{AH}$ e suas SF são valores médios obtidos de três repetições.

Promoção do crescimento radicular de plântulas tratadas com AH e suas subfrações obtidas por CGE

\section{Arabidopsis thaliana}

Para o estudo com Arabidopsis thaliana, foi obtida uma curva preliminar, variando-se concentrações de 0, 0,0001; 0,001; 0,003; 0,005; e 0,01 mol L-1 de C do $\mathrm{AH}$ e das cinco SF obtidas por CGE (SF1, SF2, SF3, SF4 e SF5) (Quadro 1). Foi analisado o número de raízes laterais emergidas. Após análise de regressão, foram estabelecidos os ensaios de comparação entre as SF.

Sementes de Arabidopsis thaliana ecótipo columbia 4 (co4) foram desinfestadas superficialmente pela imersão em etanol $95 \%$ (v/v) por cinco minutos, seguida de imersão em $\mathrm{NaClO} 20 \%$ por mais sete minutos. Após cinco lavagens com água destilada, as sementes foram colocadas para germinar e crescer em um minissistema hidropônico. Esse sistema é dividido em compartimentos que suportam dez sementes que germinam e crescem verticalmente entre uma camada de papel-filtro e outra de tecido sintético de malha fina (poliprint). A estrutura de cultivo é aberta tanto na parte superior como na inferior e coberta lateralmente com plástico preto, para evitar a passagem de luz às raízes. Após a semeadura, as sementes foram colocadas por $24 \mathrm{~h}$ a $8^{\circ} \mathrm{C}$ no escuro e, em seguida, transferidas para câmara BOD, com $25^{\circ} \mathrm{C}, 50 \mathrm{mmol} \mathrm{m}^{-2} \mathrm{~s}^{-1}$ de densidade de fluxo de fótons fotossintéticos e $14 \mathrm{~h}$ de fotoperíodo.

Após cinco dias de germinação, foi realizado o desbaste das plântulas, deixando-se cinco plantas por estrutura de cultivo, e adicionados $4 \mathrm{~mL}$ da solução de AH e suas subfrações na concentração ótima prevista pelo ensaio preliminar (Quadro 1). No tratamento controle, foram aplicados somente $4 \mathrm{~mL}$ de água destilada. Após a aplicação dos tratamentos, as estruturas de cultivo foram inseridas num reservatório mantido com água por $48 \mathrm{~h}$ e, em seguida, foi adicionada solução de Hoagland modificada para concentração final de $\mathrm{N}$ igual a $0,0001 \mathrm{~mol} \mathrm{~L}^{-1}$ (Forde \& Zhang, 1998). Duas semanas após aplicação dos tratamentos, as plântulas foram colhidas e tiveram suas raízes coradas com azul de toluidina $(0,05 \%)$, sendo digitalizadas (resolução de $300 \mathrm{dpi}$ ) para análise do crescimento do sistema radicular por meio do processamento eletrônico das imagens. Foram consideradas, para esta análise, três plantas por placa correspondente às plantas da posição central de cada placa. A arquitetura radicular foi avaliada por meio da análise do número de raízes laterais, área radicular e comprimento total do sistema radicular. Foi utilizado programa computacional para análise digital de imagem Delta-T Scan ${ }^{\text {TM }}$ (Delta-T Devices, Cambridge, UK).

Foi utilizado o delineamento experimental inteiramente ao acaso, com três estruturas de cultivo e três plantas por estrutura $(3 \times 3=9$ plantas por tratamento). Realizou-se a análise de variância, e as médias foram comparadas pelo teste DMS ( $p<0,05)$,

Quadro 1. Modelos de dose-resposta, coeficiente de correlação, desvio-padrão da regressão, p e ponto de inflexão para o número de raízes laterais emergidas de Arabidopsis thaliana após o tratamento com a solução de ácidos húmicos (AH), bem como com suas subfrações (SF) obtidas por CGE $(\mathrm{n}=15)$

Tratamento Modelo $\left(\hat{\mathrm{y}}=\mathrm{cx}^{2}+\mathrm{bx}+\mathrm{a}\right) \quad \mathrm{R}^{2} \quad$ Desvio-padrão $\quad P<\quad$ Inflexão $(\mathrm{dx} / \mathrm{dy}=\mathrm{zero})$

$\begin{array}{llllll}\text { AH } & \hat{y}=-0,2592 x^{2}+2,4238 x+4,5877 & 0,9327 & 1,29 & 0,016 & 5,10 \\ \text { SF1 } & \hat{y}=-0,2344 x^{2}+2,5562 x+3,7955 & 0,9487 & 1,12 & 0,010 & 4,68 \\ \text { SF2 } & \hat{y}=-0,3352 x^{2}+3,3716 x+3,2758 & 0,9695 & 1,13 & 0,004 & 5,27 \\ \text { SF3 } & \hat{y}=-0,3246 x^{2}+3,4002 x+2,5976 & 0,9644 & 1,19 & 0,004 & 5,03 \\ \text { SF4 } & \hat{y}=-0,2664 x^{2}+2,8497 x+4,9306 & 0,9055 & 1,74 & 0,031 & 5,24 \\ \text { SF5 } & \hat{y}=-0,2798 x^{2}+2,8544 x+4,0175 & 0,9592 & 1,14 & 0,007 & 5,35\end{array}$


pelo programa SAEG (Sistema de Análises Estatísticas e Genéticas) da Universidade Federal de Viçosa (UFV).

\section{Milho}

Plântulas de milho (híbrido UENF 506-6) foram crescidas durante sete dias em meio mínimo contendo $0,002 \mathrm{~mol} \mathrm{~L}^{-1} \mathrm{de} \mathrm{CaCl}_{2}$ (controle) ou suplementado com $\mathrm{AH}$ ou suas frações de massa molecular diferente (SF1, SF2, SF3, SF4 e SF5) na concentração equivalente a $0,002 \mathrm{~mol} \mathrm{~L}^{-1}$ de C. As plântulas foram coletadas para avaliação da área radicular, utilizandose o mesmo programa (Delta-T Scan ${ }^{\mathrm{TM}}$ ). Raízes de plântulas de milho foram coletadas para contagem dos sítios de mitose (região de intensa divisão celular onde se origina a raiz lateral) e raízes laterais emergidas (dez repetições por tratamento), conforme Canellas et al. (2002).

As vesículas da fração microssomal (membranas do vacúolo e plasmática) foram isoladas de raízes de plântulas de milho utilizando-se a centrifugação diferencial, como descrito por De Michelis \& Spanswich (1986). Resumidamente, $10 \mathrm{~g}$ (massa de tecido fresco) de raízes de milho foram homogeneizadas usando grau e pistilo em $20 \mathrm{~mL}$ de meio de extração gelado com $0,250 \mathrm{~mol} \mathrm{~L}^{-1}$ de sacarose, $10 \%$ de glicerol (m:v), 0,5 \% de PVP-40 (polivinilpirrolidona-40 KDa), $0,002 \mathrm{~mol} \mathrm{~L}^{-1}$ de EDTA (ácido etileno diamino tetracético), 0,2 \% de BSA (albumina sérica bovina) (m:v) e $0,1 \mathrm{~mol} \mathrm{~L}^{-1}$ de tampão Tris [tris-(hidroximetil) aminometano] - $\mathrm{HCl}, \mathrm{pH} 7,8$. Imediatamente antes do uso foram adicionados $0,150 \mathrm{~mol} \mathrm{~L}^{-1}$ de $\mathrm{KCl}$, $0,002 \mathrm{~mol} \mathrm{~L}^{-1}$ de DTT (ditiotreitol) e $0,001 \mathrm{~mol} \mathrm{~L}^{-1}$ de PMSF (fluoreto de metilfenilsulfonil). A manipulação das raízes até a obtenção do homogenato, bem como as centrifugações, teve a temperatura controlada a fim de que não excedesse $4{ }^{\circ} \mathrm{C}$. Além disso, o $\mathrm{pH}$ do tampão de extração também foi monitorado durante o procedimento, mantendo-se na faixa de 7,2-7,6. Após a maceração, o homogenato resultante foi filtrado por meio de quatro camadas de gaze e submetido à centrifugação numa centrífuga himac CP (HITACHI) a $1.700 \mathrm{~g}$ durante $12 \mathrm{~min}$. O sobrenadante foi coletado e submetido a uma nova centrifugação a $10.000 \mathrm{~g}$ por 15 min numa ultracentrífuga himac CP 85b (HITACHI), utilizando o rotor P70. O sobrenadante foi submetido a nova centrifugação (100.000 $g$ por $40 \mathrm{~min}$ ). O precipitado dessa nova centrifugação, denominado fração microssomal, foi ressolubilizado em meio de ressuspensão. O precipitado foi coletado e ressuspendido em $1 \mathrm{~mL}$ de solução-tampão (glicerol $15 \%$ (v:v), DTT 0,001 $\mathrm{mol} \mathrm{L}^{-1}$, PMSF 0,001 $\mathrm{mol} \mathrm{L}^{-1}$, 0,01 mol L-1 de Tris-HCl pH 7,6 e EDTA 0,001 mol L-1) e armazenado em freezer a $-70{ }^{\circ} \mathrm{C}$ por não mais que três semanas. A concentração de proteína total contida na preparação foi dosada pelo método descrito por Bradford (1976).

A atividade de hidrólise da $\mathrm{H}^{+}$-ATPase foi determinada de acordo com o método de Fiske \& Subbarow (1925). A reação foi iniciada com a adição da proteína e interrompida por meio da adição de ácido tricloroacético (TCA) gelado para uma concentração final de $10 \%(\mathrm{v} / \mathrm{v})$. O meio de reação continha 0,01 $\mathrm{mol} \mathrm{L}^{-1}$ de Mops [ácido 3-(N-morfino) propano sulfônico]-Tris $\mathrm{pH} 6,5,0,003 \mathrm{~mol} \mathrm{~L}^{-1} \mathrm{de} \mathrm{MgCl}_{2}$, $0,1 \mathrm{~mol} \mathrm{~L}^{-1}$ de KCl, 0,001 $\mathrm{mol} \mathrm{L}^{-1}$ de ATP e $50 \mu \mathrm{g}$ de proteína. Cerca de $75 \%$ da atividade da $\mathrm{H}^{+}$-ATPase das vesículas foi inibida por $0,0002 \mathrm{~mol} \mathrm{~L}^{-1}$ de vanadato, um inibidor muito eficiente da ATPase do tipo P (De Michelis \& Spanswick, 1986). Em todos os experimentos, a atividade hidrolítica da $\mathrm{H}^{+}$-ATPase foi medida a $32{ }^{\circ} \mathrm{C}$, com ou sem vanadato, e a diferença entre essas duas atividades foi atribuída à ATPase do tipo P.

\section{RESULTADOS E DISCUSSÃO}

\section{Caracterização dos ácidos húmicos}

O conhecimento da massa molecular das SH não é uma tarefa simples. De maneira geral, o tamanho e massa moleculares das SH podem ser comparativamente avaliados utilizando-se a cromatografia em gel por exclusão de tamanho (CGE). Na figura 1 são apresentados os resultados da curva de eluição a partir de CGE do AH isolado de vermicomposto utilizado neste trabalho. A técnica permitiu a separação de três componentes majoritários, sendo um de subfração de massa molecular relativamente elevada (SF1), um de massa intermediária formado pelas SF2, SF3 e SF4 e um componente de massa relativamente menor formado pela SF5 coletada na fase final do processo cromatográfico.

Esse método tem sido extensivamente aplicado na avaliação do tamanho molecular de frações húmicas (Albuzio et al., 1989) e baseia-se na velocidade

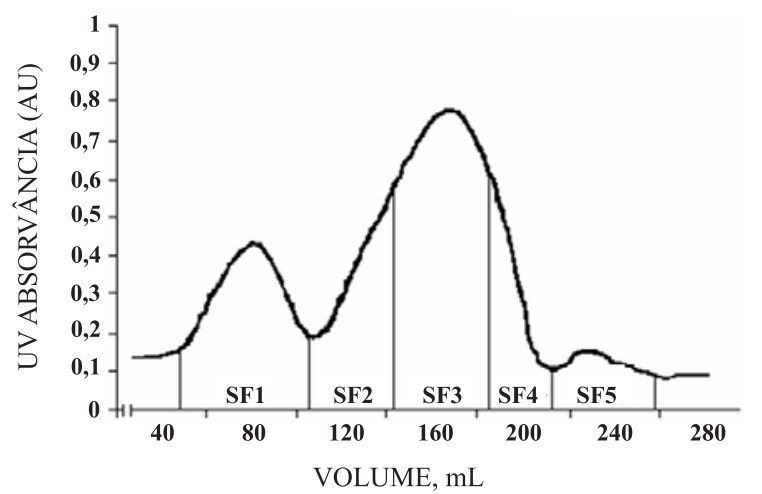

Figura 1. Curva de eluição da cromatografia em gel por exclusão de tamanho (CGE) de ácidos húmicos isolados de vermicomposto. A coluna de $40 \times 0,9 \mathrm{~cm}$ (d.i.) foi empacotada com Sephadex G-50. A fase móvel foi constituída de $\mathrm{Na}_{2} \mathrm{~B}_{4} \mathrm{O}_{7} 0,1 \mathrm{~mol} \mathrm{~L}-1+\mathrm{Na}_{4} \mathrm{P}_{2} \mathrm{O}_{7} 0,01 \mathrm{~mol} \mathrm{~L}^{-1}+\mathrm{NaCl}$ $0,01 \mathrm{~mol} \mathrm{~L}^{-1}$, pH 7,0, fluxo de $0,5 \mathrm{~mL} \mathrm{~min}^{-1}$ e detector de UV operando a $280 \mathrm{~nm}$. 
diferencial de migração dos componentes de diferentes tamanhos numa coluna com um gel específico (Sephadex $\left.{ }^{\circledR}\right)$. A diferença obtida entre as frações está mais relacionada com a distribuição de tamanho (mais precisamente do raio hidrodinâmico das moléculas) do que com a massa molecular (De Nobili \& Chen, 1999). Contudo, o termo distribuição de massa molecular ( $\mathrm{Mw}$ ) foi consagrado pelo uso e é tido como sinônimo de distribuição de tamanho molecular.

Outros fatores podem alterar a distribuição de Mw, como a presença de cargas elétricas decorrentes da dissociação de grupos funcionais e da concentração de sais, os quais provocam mudanças na conformação molecular (e, portanto, no raio hidrodinâmico das $\mathrm{SH}$ ). Esse fato não foi observado nos padrões utilizados para calibração da coluna. Além disso, com a ausência de um padrão cromatográfico válido e reconhecido para SH, é necessário o uso de proteínas globulares, carboidratos e mesmo polímeros orgânicos para calibração das colunas. Consequentemente, a distribuição da Mw pode não resultar em valor absoluto, mas só aparente e relativo aos padrões utilizados na calibração da coluna.

Para atenuar esses problemas, as SF obtidas por CGE foram analisadas por HPSEC, o qual é menos sujeito às condições operacionais (Conte \& Piccolo, 1999). Os cromatogramas obtidos por esse método são apresentados na figura 2 , e os valores relativos de distribuição de massa molecular aparente e relativa aos padrões utilizados e a medida da homogeneidade das SH por meio da polidispersividade $(\rho)$ são apresentados no quadro 2.

Como esperado, a SF1 obtida nos primeiros volumes de eluição é a fração com Mw relativa maior, correspondendo a $72 \%$ da $\mathrm{Mw}$ aparente do $\mathrm{AH}$ que não sofreu o processo de CEG. Teoricamente, era

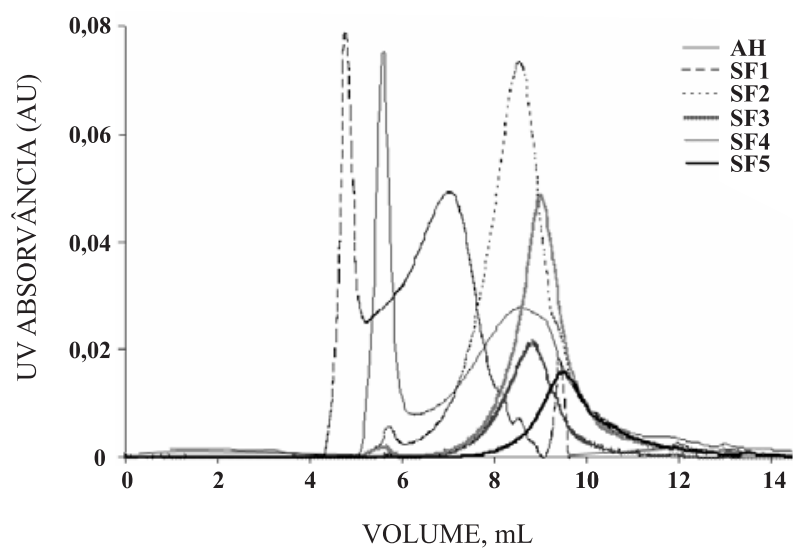

Figura 2. Perfil cromatográfico das subfrações de ácidos húmicos (AH) obtidos por HPSEC. Coluna BioSep- SEC $30 \times 0,78 \mathrm{~cm}$ (d.i) e $5 \mu \mathrm{m}$ de diâmetro de poros. $\mathrm{O}$ tampão fosfato $\mathrm{NaH}_{2} \mathrm{PO}_{4}$ $0,0625 \mathrm{~mol} \mathrm{~L}^{-1}, \mathrm{pH} 7,0$, foi usado como fase móvel com fluxo de $1,5 \mathrm{~mL}$ min e detector de UV operando a $280 \mathrm{~nm}$.
Quadro 2. Massa molecular aparente e relativa aos padrões utilizados (Mw), variação das subfrações (SF) em relação ao ácido húmico $(\mathrm{AH})$ não fracionado $(\Delta \%)$ e medida da homogeneidade das $\mathrm{SH}$ por meio da polidispersividade $(\rho)$

\begin{tabular}{crrl}
\hline Tratamento & Mw (Da) & $\boldsymbol{\Delta} \%$ & $\boldsymbol{\rho}$ \\
\hline AH & 9.058 & 0 & 1,3 \\
SF1 & 15.579 & 72 & 1,21 \\
SF2 & 7.061 & -22 & 1,18 \\
SF3 & 6.401 & -29 & 1,05 \\
SF4 & 10.468 & 16 & 5,75 \\
SF5 & 4.060 & -55 & 1,14 \\
\hline
\end{tabular}

esperado um comportamento linear decrescente para a distribuição da Mw de acordo com o aumento do volume de eluição. No entanto, a SF4 apresentou distribuição de Mw relativa maior do que a de SF3 (Figura 2). Piccolo et al. (2001) sugeriram um comportamento cromatográfico de AH em solução compatível com uma suposta estrutura supramolecular das SH, formada por moléculas heterogêneas reunidas em agregados por ligações hidrofóbicas fracas capazes de provocar interações na absorção de luz dos cromóforos, alterando a absortividade das moléculas e promovendo novos arranjamentos. Essas interações podem estar associadas a mudanças no perfil da cromatografia por exclusão e não necessariamente refletem aumentodiminuição de Mw. Em outras palavras, o aumento da intensidade de absorção de luz a $280 \mathrm{~nm}$ observado na SF4 pode estar mais associado à interação de cromóforos (hipercromia) do que ao aumento de massa molecular.

O valor $\rho$ representa a relação entre a massa molecular (Mwi) e o número de moléculas distintas presentes na amostra (Mni). Portanto, quanto mais próxima da unidade, mais homogênea será a amostra. Somente a SF4 apresentou valor de $\rho$ bem superior a 1 (Quadro 2), caracterizando-se como uma mistura molecular mais heterogênea em relação às outras SF.

De modo geral, a HPSEC confirmou a eficiência da cromatografia preparativa em gel de Sephadex G50 em separar SF de AH mais homogêneas e de distribuição de Mw relativamente distinta. Apesar da distribuição de Mw variar em uma faixa ampla nos AH e nas SF, a sua análise da composição elementar indica a presença de material húmico com pequenas faixas de variações no conteúdo de C (47,9-49,4\%) e na acidez total (Quadro 3). No entanto, a SF2 apresentou conteúdo maior de $\mathrm{N}$ e, consequentemente, menor relação $\mathrm{C} / \mathrm{N}$.

\section{Crescimento radicular}

Diferentes concentrações das cinco subfrações obtidas por cromatografia foram testadas quanto à 
Quadro 3. Análise elementar, conteúdo de grupos ácidos funcionais e raio atômico do ácido húmico (AH) e suas subfrações (SF)

\begin{tabular}{|c|c|c|c|c|c|c|c|c|c|c|}
\hline \multirow{2}{*}{ Tratamento } & \multirow{2}{*}{$\mathbf{C}$} & \multirow{2}{*}{$\mathbf{H}$} & \multirow{2}{*}{$\mathbf{N}$} & \multirow{2}{*}{$\mathbf{O}$} & \multicolumn{3}{|c|}{ Acidez } & \multicolumn{3}{|c|}{ Raio atômico } \\
\hline & & & & & Total & Carboxílica & Fenólica & $\mathrm{C} / \mathrm{N}$ & $\mathrm{H} / \mathrm{C}$ & $\mathrm{O} / \mathrm{C}$ \\
\hline & & & & - & 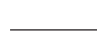 & $-\mathrm{cmol}_{\mathrm{c}} \mathrm{kg}^{-1}$ & & & & \\
\hline $\mathrm{AH}$ & 48.5 & 5.6 & 3.2 & 42.2 & 666,0 & 496,0 & 170,0 & 17.7 & 1.4 & 0.65 \\
\hline SF1 & 49,4 & 5,2 & 3,7 & 41,8 & 657,7 & 494,0 & 170,3 & 15,9 & 1,2 & 0,64 \\
\hline $\mathrm{SF} 2$ & 49,2 & 5,8 & 4,8 & 40,2 & 671,0 & 510,0 & 161,0 & 12,0 & 1,4 & 0,61 \\
\hline SF3 & 47,9 & 5,3 & 3,1 & 43,6 & 680,0 & 497,0 & 183,0 & 20,2 & 1,3 & 0,68 \\
\hline $\mathrm{SF} 4$ & 48,2 & 5,6 & 3,4 & 42,8 & 664,0 & 507,0 & 157,0 & 16,5 & 1,4 & 0,67 \\
\hline SF5 & 48,3 & 5,7 & 3,6 & 42,4 & 656,0 & 503,0 & 153,0 & 16,4 & 1,4 & 0,66 \\
\hline
\end{tabular}

sua capacidade de estimular o crescimento radicular de plantas de $A$. thaliana (Quadro 1). Os dados obtidos nos ensaios de dose-resposta para AH/SF e a indução de raízes laterais ajustaram-se a um modelo quadrático com concentração ótima das diferentes frações variando entre 0,00468 e $0,00535 \mathrm{~mol} \mathrm{~L}^{-1}$ de $\mathrm{C}$ (Quadro 1). Dessa forma, plântulas de Arabidopsis tratadas com a concentração ótima de cada SF tiveram sua arquitetura radicular significativamente modificada (Figura 3). O número de raízes laterais emergidas foi 100 a $160 \%$ superior nas plantas tratadas com $\mathrm{AH}$ e com suas $\mathrm{SF}$, em comparação com as plantas controle (Figura 3a). A indução de raízes laterais é o resultado da influência das SH sobre o crescimento radicular, já demonstrada para plântulas de milho (Canellas et al., 2002; Zandonadi et al., 2006) e Arabidopsis (Dobbss et al., 2007). O comprimento total das raízes (raiz principal + raiz lateral) também foi significativamente alterado pela adição dos $\mathrm{AH}$ e suas SF na solução de cultivo, sendo esse efeito significativo para todos os tratamentos em relação ao controle (Figura 3b). A redução do comprimento da raiz primária foi observada no tratamento com $\mathrm{AH}$ e nas SF2 e SF4, enquanto as SF1, SF3 e SF5 estimularam o crescimento do eixo principal em relação ao controle (Figura 3b).

O incremento na indução de raízes laterais está diretamente relacionado com o fitormônio auxina, pois este atua nos estádios iniciais de formação do primórdio radicular, ativando a divisão das células do periciclo (Casimiro et al., 2001). A ação do tipo auxínica presente em $\mathrm{SH}$ já foi previamente demonstrada (O’Donnell, 1973; Canellas et al., 2002), bem como a expansão celular promovida por AH (Vaughan et al., 1974). Esses eventos podem ser relacionados com a teoria do crescimento ácido promovido por auxinas (Hager et al., 1991; Rayle \& Cleland, 1992). Nesse sentido, concentrações elevadas de auxinas (menores que $10^{-6} \mathrm{~mol} \mathrm{~L}^{-1}$ ) induzem o encurtamento da raiz principal e o aumento das laterais (Blakely et al., 1988). Zandonadi et al. (2006) verificaram que concentrações muito pequenas de auxinas (menores que $10^{-10} \mathrm{~mol} \mathrm{~L}^{-1}$ ) promovem o crescimento do eixo principal. A presença de auxina nas SH foi previamente demonstrada por diferentes técnicas (Muscolo et al., 1998; Canellas et al., 2002; Quaggiotti et al., 2004). Portanto, é provável que as SF2 e SF4 possuam características químicas específicas que resultem na inibição da raiz primária, como, por exemplo, maior concentração de auxinas

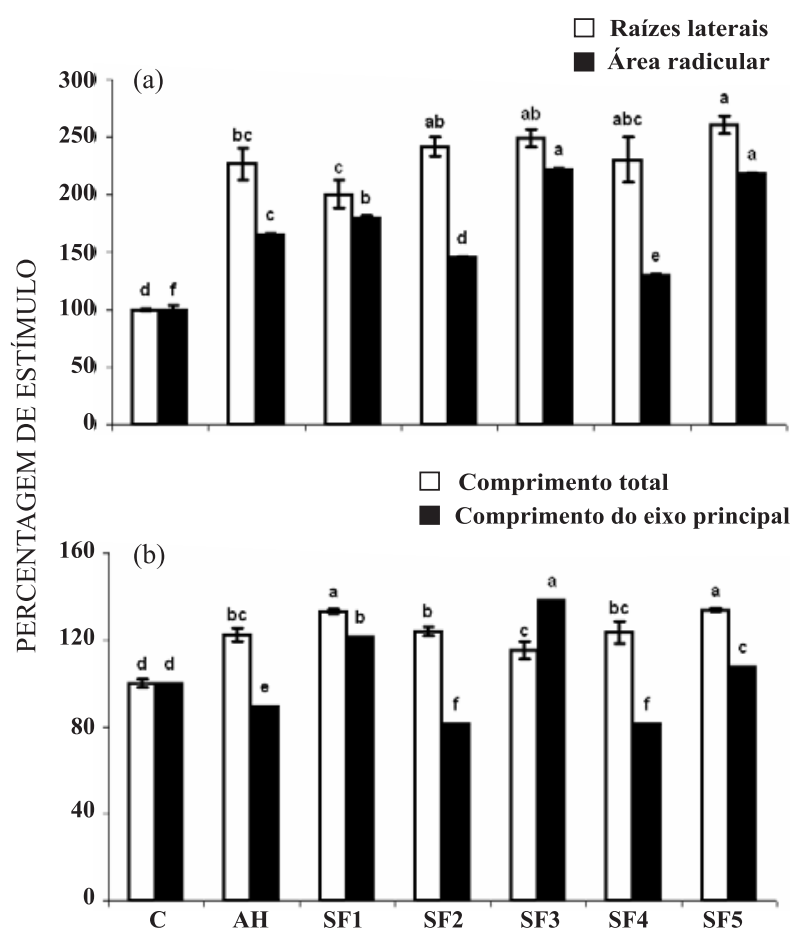

Figura 3. Efeito do AH e suas subfrações (dose ótima para emissão de raízes laterais) isolados de vermicomposto sobre a arquitetura do sistema radicular de Arabidopsis thaliana. Dados do número de raízes laterais e área radicular (a); comprimento total das raízes e comprimento do eixo principal (b), representando a média de nove plantas \pm desvio-padrão. Os dados foram normalizados em relação ao controle $(C=100 \%)$. Médias seguidas de letras diferentes em cada coluna (branca e preta) são estatisticamente diferentes pelo teste DMS $p<0,05$. 
em suas estruturas. Se por um lado foi observada correlação negativa significativa entre a Mw e a indução da emergência de raízes laterais, por outro, não se observou correlação significativa entre Mw, comprimento do eixo principal, área radicular ou comprimento total das raízes (Quadro 4).

Esses resultados corroboram a hipótese de que o efeito de estimulação sobre o crescimento radicular vegetal é, pelo menos em parte, independente da $\mathrm{Mw}$ das $\mathrm{SH}$. Assim como ocorre na presença de auxinas, a aplicação de AH resulta em indução de raízes e expansão celular, associada ao aumento da atividade bioquímica e expressão dos genes que codificam para as ATPases (Canellas et al., 2002; Zandonadi et al., 2006).

$\mathrm{O}$ resultado da aplicação de $\mathrm{SH}$ sobre o crescimento vegetal pode variar conforme a origem das $\mathrm{SH}$, a dose utilizada e a espécie vegetal em estudo (Vaughan \& Malcolm, 1985). No presente trabalho, a mudança na arquitetura radicular também foi avaliada em plântulas de milho, na concentração apropriada à espécie (0,002 $\mathrm{mol} \mathrm{L}^{-1}$ de $\left.\mathrm{C}\right)$, determinada previamente (Canellas et al., 2002). O AH aumentou em pelo menos quatro vezes o número de sítios formadores de raízes laterais (sítios de mitose) e estimulou em cerca de $20 \%$ a emissão de raízes, resultando numa área radicular quase $85 \%$ maior do que a de plântulas de milho não tratadas (controle) (Figura 4). As SF obtidas do AH também estimularam a emergência de raízes laterais, especialmente as SF1, SF2 e SF5 (Figura 4a).

Com base nesses resultados, é possível confirmar pelo menos duas premissas estabelecidas anteriormente por Vaughan \& Malcolm (1985): (1) espécies vegetais diferentes respondem de maneira específica ao mesmo material húmico estudado; e (2) as doses ótimas utilizadas também são peculiares a cada espécie estudada. $\mathrm{O}$ AH aumentou em mais de quatro vezes a atividade da $\mathrm{H}^{+}$-ATPase sensível a vanadato, enquanto o estímulo da SF que mais

Quadro 4. Matriz de correlação de Pearson entre promoção do crescimento radicular de Arabidopis thaliana e da atividade de hidrólise da H+-ATPase de membrana plasmática isolada de vesículas de raízes de milho e a distribuição de massa molecular (Mw) do ácido húmico e suas subfrações húmicas obtidas por CGE

\begin{tabular}{ccccccccc}
\hline & \multicolumn{8}{c}{ Matriz de correlação } \\
\cline { 2 - 8 } & SF & NRL & AREA & COMP & CEP & ATP & Mw \\
\hline Mw & $-0,502$ & $-0,983$ & $-0,413$ & 0,254 & 0,030 & 0,774 & 1
\end{tabular}

SF: subfrações (1, 2, 3, 4 e 5); NRL: número de raízes laterais emergidas do eixo principal; AREA: área radicular; COMP: comprimento radicular total, dado pela soma do comprimento do eixo principal (CEP) + comprimento das raízes laterais; ATP: atividade de hidrólise da $\mathrm{H}^{+}$-ATPase.

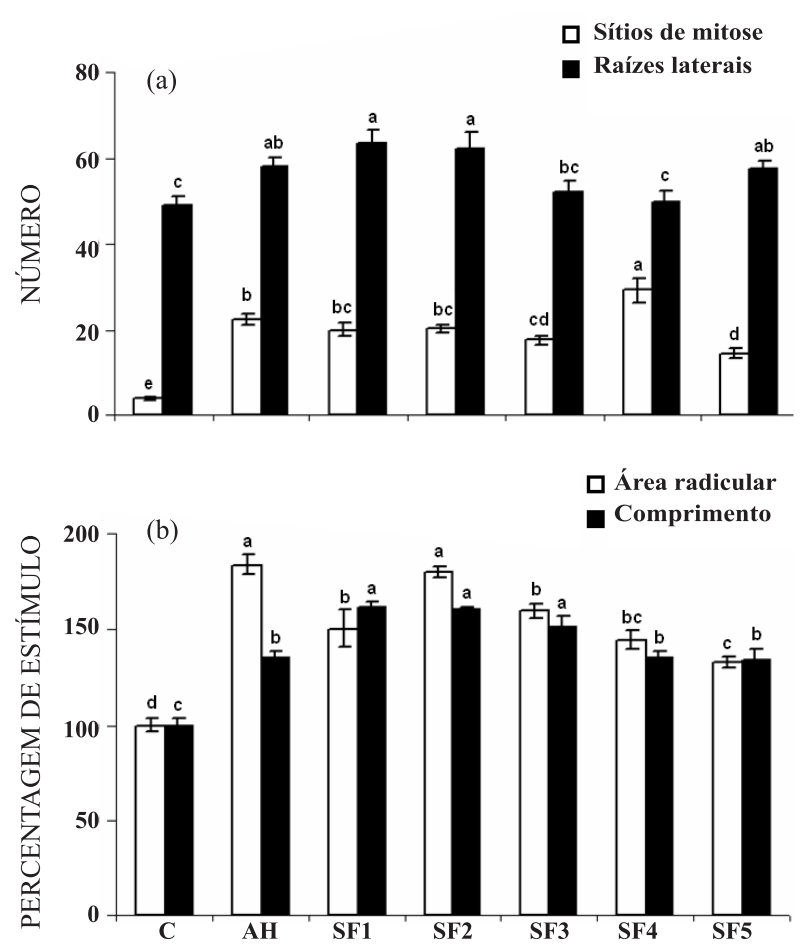

Figura 4. Efeito de AH e suas subfrações $\left(0,002 \mathrm{~mol} \mathrm{~L}^{-1}\right.$ de $\mathrm{C}$ ) isolados de vermicomposto sobre a arquitetura do sistema radicular de milho. Dados do número de sítios de mitose e de raízes laterais (a); área radicular e comprimento total das raízes (b), representando a média de 10 plantas \pm desvio-padrão. Os dados da área radicular e do comprimento total por planta foram normalizados em relação ao controle $(C=100 \%)$. Médias seguidas de letras diferentes em cada coluna (branca e preta) são estatisticamente diferentes pelo teste DMS $(p<0,05)$.

estimulou essa enzima (SF2) foi pouco maior do que duas vezes (Quadro 5). A ordem de estímulo das frações foi SF2 > SF5 > SF1 > SF4. As SF3 e SF4 pouco alteraram a atividade enzimática (Quadro 5). A SF3 reduziu a atividade da $\mathrm{H}^{+}$-ATPase em cerca de $10 \%$, e a SF4 a aumentou em cerca de $15 \%$. A ativação da ATPase parece estar relacionada com o aumento do desenvolvimento radicular em plântulas de milho (Quaggiotti et al., 2004; Zandonadi et al., 2006). No presente trabalho foi verificado que essa ativação por $\mathrm{AH}$ pode ser parte do fenômeno responsável pelo aumento do número de sítios de mitose e raízes laterais, o que resulta em maior área radicular (Figura 4a,b). As SF1, SF2 e SF5 reproduziram esse mesmo comportamento (Figura 4a). As SF3 e SF4 foram as que menos modificaram a atividade da ATPase e a emissão de raízes laterais (Quadro 5 e Figura 4a).

Piccolo et al. (1996) e Simpson (2002) observaram a mobilidade dos constituintes químicos das $\mathrm{SH}$ de alta para baixa massa molecular quando em contato 
Quadro 5. Atividade de hidrólise de ATP específica da $\mathrm{H}^{+}$-ATPase de membrana plasmática de vesículas microssomais isoladas de raízes de plântulas de milho tratadas ou não por sete dias com ácidos húmicos (AH) e suas diferentes subfrações (SF) obtidas por CGE

\begin{tabular}{ccc}
\hline Tratamento & $\begin{array}{c}\text { Atividade } \\
\text { hidrolítica }\end{array}$ & $\begin{array}{c}\text { Incremento } \\
\text { relativo }\end{array}$ \\
\hline Controle & $\mu$ mol $\mathrm{mg}^{-1} \mathrm{~min}^{-1} \mathrm{Pi}$ & $\%$ \\
AH & $0,67 \pm 0,022$ & 100 \\
SF1 & $3,76 \pm 0,180$ & 561 \\
SF2 & $0,90 \pm 0,092$ & 134 \\
SF3 & $1,42 \pm 0,032$ & 212 \\
SF4 & $0,61 \pm 0,027$ & 91 \\
SF5 & $0,77 \pm 0,049$ & 115 \\
\end{tabular}

com ácidos orgânicos. Nardi et al. (2004) observaram elevada bioatividade em $\mathrm{SH}$ isoladas com ácidos orgânicos de cadeia curta. Canellas et al. (2008a) e Façanha et al. (2002) verificaram que plântulas de milho e café têm capacidade de modificar o perfil de exsudação de ácidos orgânicos em resposta à adição de $\mathrm{AH}$, sugerindo a presença de um "diálogo químico“ ainda não muito claro entre a planta e a solução com SH. Além disso, Canellas et al. (2008c) encontraram correlação significativa entre o grau de hidrofobicidade de AH e sua capacidade de promoção do crescimento radicular. Nos domínios hidrofóbicos da matéria orgânica, a atividade da água e dos microrganismos é menor (Kleber et al., 2007), concorrendo dessa forma para a preservação de biopolímeros resultantes da decomposição de resíduos de plantas ou da atividade de microrganismos (Spaccini et al., 2002; Sutton \& Sposito, 2005).

Assim, a presença e magnitude de promoção do crescimento radicular das SH não apresenta uma resposta uniforme em relação à distribuição da massa molecular e parece estar mais associada à presença $\mathrm{e}$ concentração de compostos bioestimulantes como hormônios vegetais nos agregados húmicos. A elucidação da relação estrutura-atividade de SH ainda está longe de ser claramente compreendida, porém é um desafio que deve ser enfrentado para a busca e otimização do uso de promotores de crescimento vegetal tendo como base substâncias húmicas.

\section{CONCLUSÕES}

A distribuição da massa molecular de $\mathrm{AH}$ apresentou correlação inversa e significativa com a estimulação de raízes laterais em plântulas de
Arabidopsis. Entretanto, o comprimento de raízes laterais, o comprimento do eixo principal e a área radicular em plântulas de Arabidopsis e milho não apresentaram correlação significativa com a distribuição da massa molecular de AH. Assim, a atividade de estimulação do crescimento radicular parece estar mais relacionada com a diversidade e funcionalidade estrutural e sua associação com compostos bioestimulantes das substâncias húmicas do que com a distribuição de massa molecular dos agregados húmicos.

\section{AGRADECIMENTOS}

Ao CNPq (474024/2007), FAPERJ (E-26/152.6102006) e IFS (c3391-2), pelo suporte financeiro. Ao sr. Francisco Maurício Alves Francelino, pela ajuda no procedimento CGE, e ao prof. Carlos Jorge Logullo de Oliveira e ao MSc. Evenilton Pessoa Costa, pelo suporte técnico na instrumentação HPSEC.

\section{LITERATURA CITADA}

ALBUZIO, A.; NARDI, S. \& GULLI, A. Plant growth regulator activity of small molecular size humic fractions. Sci. Total Environ., 81/82:671-674, 1989.

BLAKELY, L.M.; BLAKELY, R.M.; COLOWIT, P.M. \& ELLIOTT, D.S. Experimental studies on lateral root formation in radish seedling roots. Plant Physiol., 87:414419,1988

BRADFORD, M.M. A rapid and sensitive method for the quantitation of microgram quantities of protein utilizing the principle of protein-dye binding. Anal. Biochem., 72:248-254, 1976.

CABANISS, S.E.; ZHOU, Q.; MAURICE, P.A.; CHIN, Y.P. \& AIKEN, G.R. A log-normal distribution model for the molecular weight of aquatic fulvic acids. Environ. Sci. Technol., 34:1103-1109, 2000.

CANELLAS, L.P.; OLIVARES, F.L.; OKOROKOVAFAÇANHA, A.L. \& FAÇANHA, A.R. Humic acids isolated from earthworm compost enhance root elongation, lateral root emergence, and plasma membrane $\mathrm{H}^{+}$-ATPase activity in maize roots. Plant Physiol., 130:1951-1957, 2002.

CANELLAS, L.P.; TEIXEIRA JUNIOR, L.R.L.; DOBBSS, L.B.; SILVA, C.A.; MÉDICI, L.O.; ZANDONADI, D.B. \& FAÇANHA, A.R. Humic acids crossinteractions with root and organic acids. Ann. Appl. Biol., 153:157-166, 2008a.

CANELLAS, L.P.; MENDONCA, E.S.; DOBBSS, L.B.; BALDOTTO, M.A.; VELLOSO, A.C.X. \& AMARALSOBRINHO, N.M.B. Reações da matéria orgânica. In: SANTOS, G.A.; SILVA, L.S.; CANELLAS, L.P. \& CAMARGO, F.A.O. Fundamentos da matéria orgânica do solo: Ecossistemas tropicais e sub-tropicais. 2.ed. Porto Alegre, Metrópole, 2008b. p.45-53. 
CANELLAS, L.P.; ZANDONADI, D.B.; BUSATO, J.G.; BALDOTTO, M.A.; SIMOES, M.L.; MARTIN-NETO, L.; FAÇANHA, A.R.; SPACCINI, R. \& PICCOLO, A. Bioactivity and chemical characteristics of humic acids from tropical soils sequence technical articles. Soil Sci., 173:624-637, 2008c.

CASIMIRO, I.; MARCHANT, A.; BHALERAO, R.P.; BEECKMAN, T.; DHOOGE, S.; SWARUP, R.; GRAHAM, N.; INZE, D.; SANDBERG, G.; CASERO, P.J. \& BENNETT, M. Auxin transport promotes Arabidopsis lateral root initiation. Plant Cell, 13:843-852, 2001.

CONTE, P. \& PICCOLO, A. High pressure size exclusion chromatography (HPSEC) of humic substances. Molecular sizes, analytical parameters, and columns performance. Chemosphere, 38:517-528, 1999.

DE MICHELIS, M.I \& SPANSWICK, R.M. $\mathrm{H}^{+}$-Pumping driven by the vanadate-sensitive ATPase in membrane vesicles from corn roots. Plant Physiol., 81:542-547, 1986.

DE NOBILI, M. \& CHEN, Y. Size exclusion chromatography of humic substances: Limits, perspectives and prospectives. Soil Sci., 164:825-833, 1999.

DOBBSS, L.B.; MEDICI, L.O.; PERES, L.E.P.; PINO-NUNES, L.E.; RUMJANEK, V.M.; FAÇANHA, A.R. \& CANELLAS, L.P. Changes in root development of Arabidopsis promoted by organic matter from Oxisols. Ann. Appl. Biol., 151:99-111, 2007.

FAÇANHA, A.R.; OLIVARES, F.L.; VELLOSO, A.C.X.; BRAZFILHO, R.; SANTOS, G.A. \& CANELLAS, L.P. Bioatividade de ácidos húmicos: Efeitos sobre o desenvolvimento radicular e sobre a bomba de prótons da membrana plasmática. Pesq. Agropec. Bras., 37:13011310,2002

FISKE, C.F. \& SUBBAROW, Y. The colorometric determination of phosphorus. J. Biol. Chem., 66:375, 1925 .

FORDE, B.G. \& ZHANG, H. An Arabidopsis MADS box gene that controls nutrient-induced changes in root architecture. Science, 279:407-409, 1998.

HAGER, A.; DEBUS, G.; EDEL, H.G.; STRANSKY, H. \& SERRANO, R. Auxin induces exocytosis and rapid synthesis of a high-turnover pool of plasma-membrane $\mathrm{H}^{+}$-ATPase. Planta, 185:527-537, 1991.

JANOS, P. Separation methods in the chemistry of humic substances. J. Chromatogr. A, 983:1-18, 2003.

JANOŠ, P. \& ZATØREPÁLKOVÁ, I. High-performance size exclusion chromatography of humic substances on the hydroxyethyl methacrylate colum. J. Cromatogr., A. 1160:160-165, 2007.

KLEBER, M.; SOLLINS, P. \& SUTTON, R. A conceptual model of organo-mineral interactionc in soils: Self-assembly of organic molecular fragments into zonal structures on mineral surfaces. Biogeochemistry, 85:9-24, 2007.

MUSCOLO, A.; CUTRUPI S. \& NARDI, S. IAA detection in humic substances. Soil Biol. Biochem., 30:1199-1201, 1998.
MUSCOLO A.; SIDARI M.; ATTINA E.; FRANCIOSO O.; TUGNOLI V. \& NARDI S. Biological activity of humic substances is related to their chemical structure. Soil Sci. Soc. Am. J., 71:75-85, 2007.

NARDI, S.; PIZZEGHELLO, D.; MUSCOLO, A. \& VIANELLO, A. Physiological effects of humic substances on higher plants. Soil Biol. Biochem., 34:1527-15336, 2002.

NARDI, S.; MORARI, F.; BERTI, A.; TOSONI, M. \& GIARDINI, L. Soil organic matter properties after 40 years of different use of organic and mineral fertilisers. Europ. J. Agron., 21:357-367, 2004.

NARDI, S.; MUSCOLO, A. \& VACCARO, S. Relationship between molecular characteristics of soil humic fractions and glycolytic pathway and krebs cycle in maize seedlings. Soil Biol. Biochem., 39:3138-3146, 2007.

O'DONNELL, R.W. The auxin-like effects of humic preparations from leonardite. Soil Sci., 116:106-112, 1973.

PEURAVUORI, J. \& PIHLAJA, K. Advanced TMAH and TMAAc thermochemolysis-pyrolysis techniques for molecular characterization of size-separated fractions from aquatic dissolved organic matter. Anal. Bioanal., 389:475-491, 2007.

PICCOLO, A., NARDI, S. \& CONCHERI, G. Macromolecular changes of humic substances induced by interaction with organic acids. Europ. J. Soil Sci., 47:319-328, 1996.

PICCOLO, A.; CONTE, P. \& COZZOLINO, A. Chromatographic and spectrophotometric properties of dissolved humic substances compared with macromolecular polymers. Soil Sci., 166:174-185, 2001.

QUAGGiotTI, S.; RUPERTI, B.; PIZZEGHELLO, D.; FRANCIOSO, O.; TUGNOLI, V. \& NARDI, S. Effect of low molecular size humic substances on nitrate uptake and expression of genes involved in nitrate transport in maize (Zea mays L.). J. Exper. Bot., 55:803-813, 2004.

RALPH, J.P. \& CATCHESIDE, D.E.A. Size-exclusion chromatography of solubilised low-rank coal. J. Chromatogr. A, 724:97-105, 1996.

RAYLE, D.L \& CLELAND, R. The acid growth theory of auxininduced cell elongation is alive and well. Plant Physiol., 99:1271-1274, 1992.

SAITO, Y. \& HAYANO, S. Gel filtration chromatography of humic substances in soil solutions using HPLCdetermination of the molecular weight distribution. J. Chromatogr., 177:390-392, 1979.

SCHNITZER, M. \& GUPTA, U.C. Determination of acidity in soil organic matter. Soil Sci. Soc. Am. Proc., 27: 274-277, 1965 .

SIERRA, M.M.D.; GIOVANELA, M.; PARLANTI, E. \& SORIANO-SIERRA, E.J. 3D-fluorescence spectroscopic analysis of HPLC fractionated estuarine fulvic and humic acids. J. Braz. Chem. Soc., 17:113-124, 2006. 
SILVA, C.A.; ANDERSON, S.J. \& GUILHERME, L.R.G. Uso da cromatografia de exclusão por tamanho na caracterização de substâncias húmicas de Latossolo Vermelho-Escuro sob efeito da calagem. R. Bras. Ci. Solo, 24:495-503, 2000.

SIMPSON, A.J. Determining the molecular weight, aggregation, structures and interactions of natural organic matter using diffusion ordered spectroscopy. Magnetic Res. Chem., 40:S72-S82, 2002.

SPACCINI, R.; PICCOLO, A.; CONTE, P.; HABERHAUER, G. \& GERZABEK, M.H. Increased soil organic carbon sequestration through hydrophobic protection by humic substances. Soil Biol. Biochem., 34:1839-1851, 2002.

SUTTON, R. \& SPOSITO, G. Molecular structure in soil humic substances: The new view. Environ. Sci. Technol., 39:9009 -9015, 2005.

SWIFT, R.S. Macromolecular properties of soil humic substances: Fact, fiction, and opinion. Soil Sci., 164:790802, 1999.

SWIFT, R.S. \& POSNER, A.M. Gel chromatography of humic acid. J. Soil Sci., 22:237-249, 1971.
TONELli, D.; SEEBeR, R.; CIAVATTA, C. \& GESSA, C. Extraction of humic acids from a natural matrix by alkaline pyrophosphate. Evaluation of the molecular weigth of fractions obtained by ultrafiltration. Fresenius J. Anal. Chem., 359:555-560, 1997.

VAUGHAN, D. \& MALCOLM, R.E. Influence of humic substances on growth and physiological processes. Soil organic matter and biological activity. Dordrecht, Martins Nijihoff/Dr W. Junk Publisher, 1985. p.37-75.

VAUGHAN, D.; CHESIRE, M.V. \& MUNDIE, C.M. Uptake by the beet root tissue and biological activity of ${ }^{14} \mathrm{C}$-labelled fractions of soil organic matter. Trans. Biochem. Soc., 2:126-129, 1974.

ZANDONADI, D.B.; CANELLAS, L.P. \& FACANHA, A.R. Indolacetic and humic acids induce lateral root development through a concerted plasmalemma and tonoplast $\mathrm{H}^{+}$pumps activation. Planta, 225:1583-1595, 2006.

YAU, W.W.; KIRKLAND, J.J. \& BLY, D.D. Modern sizeexclusion liquid chromatography, practice of gel permeation and gel filtration chromatography. New York, John Wiley \& Sons, 1979. p.31-50. 